\title{
Ultrastructure of Light Organs of Loliginid Squids: Insights into the Morphology of Bacteriogenic Light Organs
}

\author{
R.C. Guerrero-Ferreira, ${ }^{*}$ and M.K. Nishiguchi** \\ * Emory University School of Medicine, Division of Pediatric Infectious Diseases. 2015 Uppergate \\ Drive NE. Atlanta, GA 30322 \\ ** New Mexico State University, Department of Biology, MSC 3AF. Las Cruces, NM 88001
}

Squids and octopus (Mollusca: Cephalopoda) are characterized by the presence of light-producing organs[1]. These complex organs, also known as photophores, have a variety of morphological characteristics, and range from groups of simple, light-producing cells, to specialized light organs with cells surrounded by reflectors, lenses, light guides, color filters, and muscles [2]. Bacteriogenic light organs have been well characterized in sepiolid squids, but a number of species in the family Loliginidae are also known to contain bacteriogenic light organs [3].

Comparable in complexity to the compound eyes of many animals, light organs are able to readily adjust color, intensity, and angular distribution of light produced from within [4]. In oceanic cephalopods, photophores emit intrinsic luminescence (autogenic) with different spectra of light emanating from their own photocytes [5]. In contrast, photophores of most neritic cephalopods have extrinsic (bacteriogenic) luminescence, with light produced by Vibrionaceae bacteria housed in specialized light organ complexes within the mantle cavity of their host [6]. Studies observing $E$. scolopes demonstrate that down-welling light intensity can be matched by the squids luminescence in a behavior termed counterillumination [7].

Within the family Loliginidae (Cephalopoda: Myopsida), a number of species are known to posses bilobed, bacteriogenic light organs [8]. Studies have provided evidence confirming that the pathogenic marine bacterium $V$. harveyi colonizes light organs in loliginid squid, and posed questions regarding the role of loliginid light organs as a reservoir for $V$. harveyi in the ocean. However, the morphology of loliginid light organs has not been well described in the scientific literature, most likely because their potential as $V$. harveyi niche was not yet understood.

Given that little is known about this symbiosis, this study utilized transmission and scanning electron microscopy to characterize the morphology of loliginid light organs and determine the location of bacterial symbiont cells within the tissue. Our research shows that, as observed in other light organassociated bacteria, the rod-shaped loliginid symbionts lack flagella. Also, bacterial association to the light organ epithelial tissue, as well as each other is not as prevalent as reported for other squidVibrio systems. Interestingly, SEM observations show the presence of two pores leading to the bacterial chamber. In addition, data presented here offers support for the hypothesis of the origin of bacteriogenic light organs from accessory nidamental glands in squids.

\section{References}

[1] R. E. Young, Deep-Sea Res. 19, 651 (1972).

[2] R. A. Cloney, E. Florey, Cell Tissue Res. 89, 250 (1968).

[3] M. K. Nishiguchi, J. E. Lopez, S. v. Boletzky, Evolution and Development 6, 41 (2004). 
[4] G. P. Ferguson, J. B. Messenger, Proceedings: Biological Sciences 243, 63 (1991).

[5] D. Pringgenies, J. M. Jorgensen, Acta Zoologica 75, 305 (1994).

[6] M. J. McFall-Ngai, M. K. Montgomery, Biol. Bull. 179, 332 (1990).

[7] B. W. Jones, M. K. Nishiguchi, Mar Biol 144, 1151 (2004).

[8] D. O. Alexeyev, Zool. Zhurnal 71, 12 (1992).

[9] This work was supported in part by NSF IOS 0744498 NIH-NIAID 1SC1AI081659 - 01 to M.K.N. The authors acknowledge Rami Al-Katib for his valuable contribution.
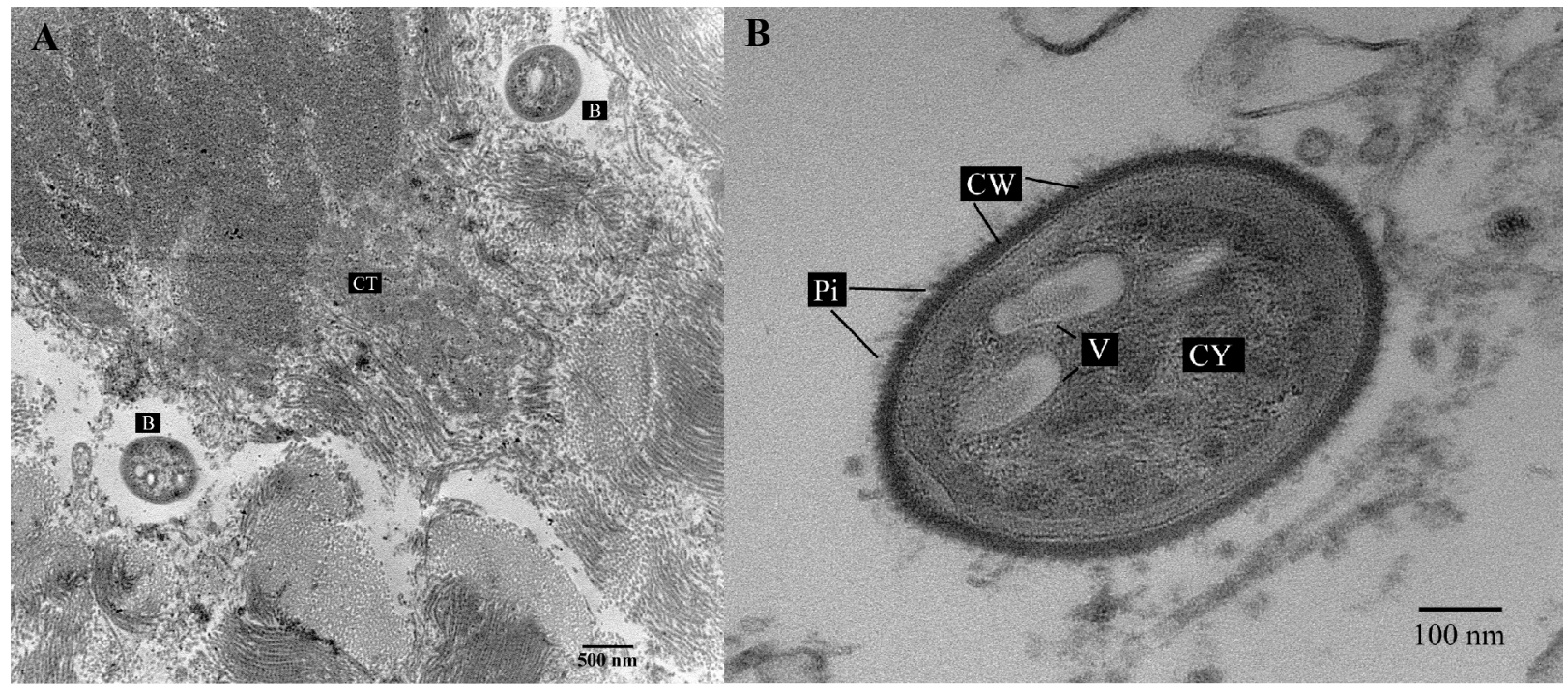

Fig. 1. TEM of bacteriogenic light organ. A. Vibrio bacteria (B) associated to Uroteuthis chinensis squid tissue (CT for connective tissue). Cells are located inside crypt spaces. B. Bacterial cell associated to the squid Uroteuthis etheridge with pili (P) and vacuoles $(\mathrm{V})$ present.

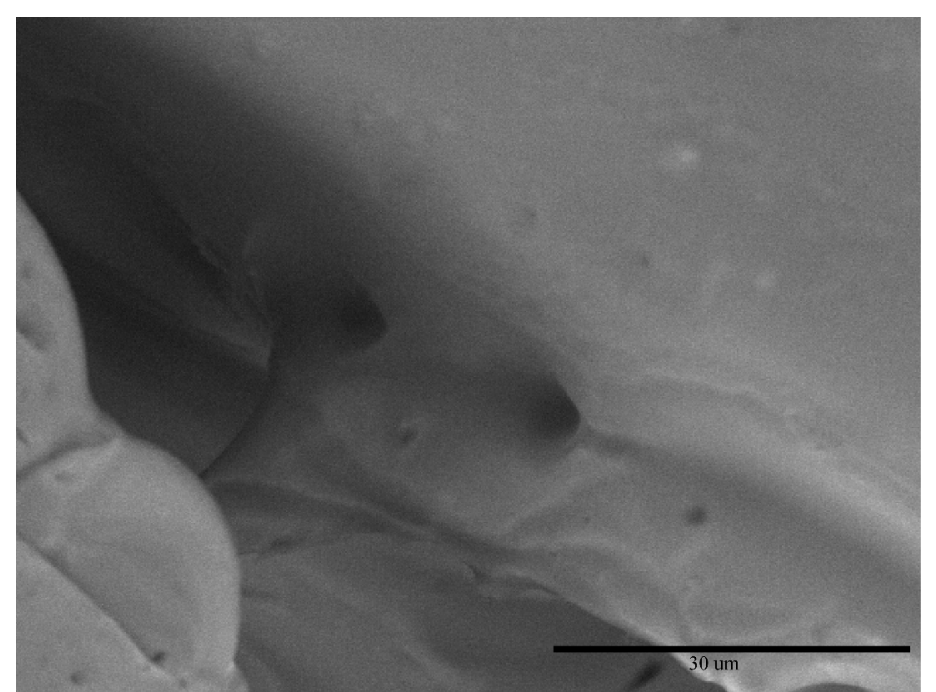

Fig. 2. Scanning electron micrograph of Uroteuthis chinensis light organ showing two pores leading into the bacterial chamber. 